\title{
Characterization of the unconfined compressive strength test in rocks by fine granulometry
}

\author{
Feijoo Calle Ernesto Patricio ${ }^{1}$ Feijoo Guevara Bernardo Andrés ${ }^{2}$ \\ \{pfeijoo,ua065330\}@uazuay.edu.ec \\ ORCID: 0000-0001-6901-79331, ORCID: 0000-0002-1089-13322 \\ Universidad del Azuay \\ Cuenca-Ecuador
}

Recibido (01/07/20), Aceptado (17/07/20)

\begin{abstract}
This work presents a proposal for the characterization of the Unconfined Compressive Strength test (UCS), through a series of operations that can be carried out without inconvenience in the field. Initially, fresh rock samples are obtained from outcrops in the area and specimens of specific dimensions are made. After the test specimen elaboration phase, crushing and granulometric classification tests are carried out with a set of specimens and in parallel with a second group, UCS tests are carried out. With the results, the rock is characterized by graphing granulometric curves and in this graph the areas of fine granulometry are focused, inserting in these areas, the average value of UCS, with which it can be identified and determined when it is really necessary and It is inevitable to send rock samples to laboratories, thus saving time and money for the mining project.
\end{abstract}

Keywords: Compression, crushing, granulometry, rock.

\section{Caracterización de la resistencia a compresión en rocas mediante granulometría fina}

\begin{abstract}
Resumen: Este trabajo presenta una propuesta para la caracterización de la Resistencia a la Compresión Simple o Uniaxial de las rocas (RCS), mediante una serie de operaciones que se pueden desarrollar sin inconvenientes en campo. Inicialmente se obtienen muestras frescas de rocas de afloramientos en la zona y se elaboran probetas de dimensiones específicas. Luego de la fase de elaboración de probetas, se ejecutan ensayos de trituración y clasificación granulométrica, con un conjunto de probetas y paralelamente con un segundo grupo se ejecutan ensayos de RCS. Con los resultados, se caracteriza la roca mediante la graficación de curvas granulométricas y en esta gráfica se enfoca las zonas de granulometría fina, insertando en dichas zonas, el valor promedio de RCS, con lo cual se puede identificar y determinar cuando realmente es necesario e inevitable enviar muestras de roca a laboratorios, logrando así un ahorro en tiempo y dinero para el proyecto minero.
\end{abstract}

Palabras Clave: Compresión, granulometría, roca, trituración

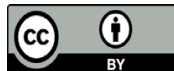




\section{I.INTRODUCTION}

Mining activities, specifically in the development of the extraction of minerals or materials in the open or underground, demand the permanent characterization of said minerals or materials, and in a special way it is of vital importance to know a fundamental parameter, to develop stability studies of mining structures, which is known as Simple or Uniaxial Compressive Strength (UCS) of the rock material. In mining it is important to determine the compressive strength of the rocks in order to develop rock mass classifications, such as the Rock Mass Rating (RMR) or Q Index, with which the stability of mining structures is determined, both at pit open as in underground. But on many occasions, it becomes tedious to permanently send samples to the laboratory to obtain the compressive strength.

This property of the rocks can be determined by sending samples to laboratories, but for many projects, due to factors such as time and cost, it represents a concern in the development of their activities. Currently the fundamental problem for mining engineers is the need to apply technical tests in situ, but it is essential to know the limitations and properties of the methods in order to establish a solution to the problem. For the above and with the use of equipment, which exist in every mining project, a strategy is proposed for the characterization of the (UCS), through crushing and granulometric analysis, in an agile, economical and feasible way in situ.

This work begins with a description of the related theoretical aspects and their determination, to then determine a methodology of laboratory work and experimentation, which can be developed in the field and finally the interpretation of results and characterization of the rock material is explained, Therefore, it is proposed to elaborate a graph with different particle distributions (granulometric curves), obtained from rock crushing processes and their respective compressive strength values, in order to correlate these values.

This proposal consists of establishing a relationship between parameters and obtaining results that allow generating security and reliability in the values that will be applied later in the methodology to determine the type of mining fortification. The advantage that this proposal offers, with respect to the measurement of rock compression in laboratories, is the optimization of time, reducing costs and labor, so it is justified to execute this type of proposal in the field.

\section{II.DEVELOPMENT}

The characterization of materials is a matter of vital importance in mining activities, so it is clear that it must be carried out taking into consideration the fundamental difference between rocky material or rocky matrix and rocky massif. Andesites, for example and broadly speaking, are fine-grained volcanic rocks, they are common, as lava flows in orogenic regions and occasionally form small intrusions. They are compact, sometimes vesicular, and commonly brown in color and in total extent they rank second after basalt $\square 1 \square$.

On the other hand, andesite itself, in its behavior as a rocky massif, can vary significantly with respect to its behavior as a rocky material. Consequently, the characterization of a rock mass has some elements to consider and its behavior may be different from that of rock material.

In the characterization of the rocky massif, from outcrops, a series of observations and field measurements are made that are the basis and systematic for it to be characterized. Must take into account:

-Number and orientation of families.

-Block size and intensity of fracturing.

-Degree of weathering.

-Rock mass resistance

It is known that it is possible and relatively cheap to test rocky material samples to characterize its mechanical behavior, since it is very difficult to directly test the rock massif, due to the large size of the samples that would have to be used. 3 .

\section{A.Rock fragmentation}

In mining processes, after the extraction of materials by means of blasting or heavy machinery, the material is subjected to a process of fragmentation or crushing, in order to disintegrate it and reach an ideal particle size, for the processes of enrichment of mineral concentrates or simply to obtain suitable materials for use in civil works.

Crushing can be primary, secondary, or tertiary. Primary crushing serves to break up the coarse material as it 
arrives from the mine or quarry, to bring it to a smaller size; the output size of the primary crushing depends on the technical characteristics of the machinery used and on energy expenditure criteria 4.

This crushing can be carried out with different equipment, such as: jaw crushers and mill or hammer crushers.

In primary crushing the blocks of material at the inlet of the crusher can be large, but the outlet of the material is generally less than $100 \mathrm{~mm}$.

\section{B.Granulometric analysis}

The granulometric analysis or particle distribution of the treated material is important in the research processes for an operation control. The separation of a material into different fractions, according to their sizes, is necessary to know its competence from a geotechnical perspective.

After the fragmentation process, the material that feeds the beneficiation and extraction operations is made up of particles with a wide range of sizes, which is why the information obtained through the granulometric analysis is necessary for: planning, monitoring and control in mineral processing 5 .

The granulometric analysis, which concerns us, is the composition, in percentage, of the various aggregate sizes in a sample that have been subjected to a mechanical classification process, by means of well-defined meshes or sieves.

By granulometry or granulometric analysis of an aggregate, it is understood any manual or mechanical procedure by means of which the constituent particles of the aggregate can be separated according to sizes, in such a way that the amounts by weight of each size that contribute the total weight can be known. To separate by size, meshes with different openings are used, which provide the maximum aggregate size in each of them 6 .

Mineral fragments are not made up of single-size particles, otherwise they come in various sizes. To describe a system of particles with a wide size range, it can be specified through the use of density and distribution functions. The distribution of sizes can be correlated by mathematical expressions, they must relate the size of the particle, that is, the opening of the mesh, with a percentage by weight, this means the weight of the sample for each sieve, it can be accumulated, retained or intern 5 .

In practice, the weights of each size are expressed as percentages retained in each mesh with respect to the total sample. These retained percentages are calculated both partial and accumulated, in each mesh, since with the latter we proceed to draw the graph of material values (granulometry)6.

Curves can be represented in various ways. The most used form provides the use of semi-logarithmic diagrams, with the abscissa (mesh sizes or classification in general) in logarithmic scale and the ordinate (percentage of passing or retained) 6. Figure 1 .

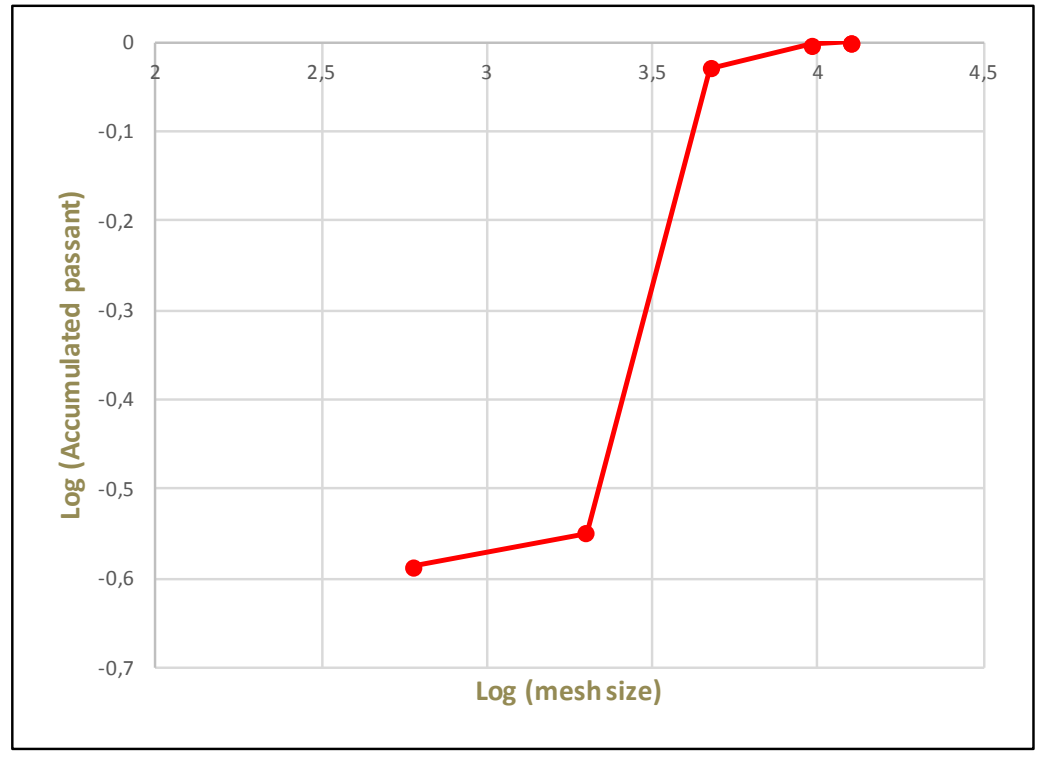

Fig. 1. Granulometric Curve 


\section{C.Particle size distribution (PSD)}

The distribution of the particles in a series of sieves or meshes can be expressed or represented in various ways, but there are already standardized models, which greatly facilitate the interpretation of these distributions.

A widely used model is that of Schumann, which was used in this proposal.

Equation (1) describes the Shumann distribution, used to represent the distribution of sizes obtained by screening, comparing the cumulative percentage through with the size of the particle.

The equation is:

$$
F_{(x)}=\left(\frac{x}{K_{s c h}}\right)^{n}
$$

Where:

F_((x) ):\% cumulative weight passing through each mesh

$\mathrm{n}$ :distribution parameter

K_sch:Schumann's constant

$\mathrm{x}:$ particle size 5 .

\section{D.Unconfined compressive strength (UCS)}

One of the important properties that must be known about rocky material is the resistance to simple or uniaxial compression (UCS), and to determine this parameter, rock samples that emerge in the reservoir must be obtained, suitable specimens prepared and sent to laboratories. for the determination of the burst pressure 7.

Equation (2) describes the simple compressive strength of the rocky matrix, it is the value obtained when a compression load is applied in a given direction, without applying any other stress in any other direction. It is usually expressed with the symbols Co or $\sigma \mathrm{c}$ :

$$
C_{o}=\frac{P}{A}
$$

Where:

P:breaking load

A:section on which it applies 8 .

This test is used to determine the compressive strength of a cylindrical rock specimen with a height between twice and three times the diameter. These specimens are usually obtained from drill cores. Samples can also be obtained from rock blocks; The extraction of these blocks in the mine or on the construction site must be carried out without blasting, since these can generate new microcracks in the rock or increase existing ones, which would result in a loss of resistance of the obtained specimens. from them. Finding out the simple compressive strength of a rock is important because it allows classifying the rock according to its resistance, it is an important parameter in the most commonly used failure criteria (Mohr-Coulomb and Hoek-Brown)9.

But many times due to the conditions in which the mining works are, it is complicated and sometimes almost impossible to send rock samples to laboratories to determine the value of the UCS, and in these times it is the problem of those in charge of evaluating the stability. structures in the field, which is why there is an urgent need to generate alternatives in situ for the assessment of UCS 10. 


\section{III.METHODOLOGY}

This work was carried out on andesite samples from the Cojitambo area, located in the province of Cañar (Ecuador) and said samples were obtained from outcrops, with the conviction that they are healthy, fresh and that they have not had any type of weathering.

Of the rock samples obtained, 30 specimens were generated by manual elaboration, which had the following dimensions: $5 \mathrm{~mm}$ x $5 \mathrm{~mm}$ x $20 \mathrm{~mm}$. These specimens were subjected to a cross section, which caused each "mother" specimen to be transformed into two "daughter" specimens, A and B, that is, daughter specimens 1A and 1B were obtained from mother specimen number 1 . The daughter specimens were approximately $5 \mathrm{~mm}$ x $5 \mathrm{~mm} \times 10 \mathrm{~mm}$.

The purpose of this cut is that daughter specimen A is subjected to a primary crushing process, by means of a MEM R22 jaw crusher and later to the granulometric classification process with a selected set of sieves. The sieves were the $12.7 \mathrm{~mm}, 9.75 \mathrm{~mm}, 4.75 \mathrm{~mm}$ and $2 \mathrm{~mm}$ apertures. The qualifying time was 2 minutes.

The crusher used and the set of sieves can be seen in Figures 2 and 3, respectively.

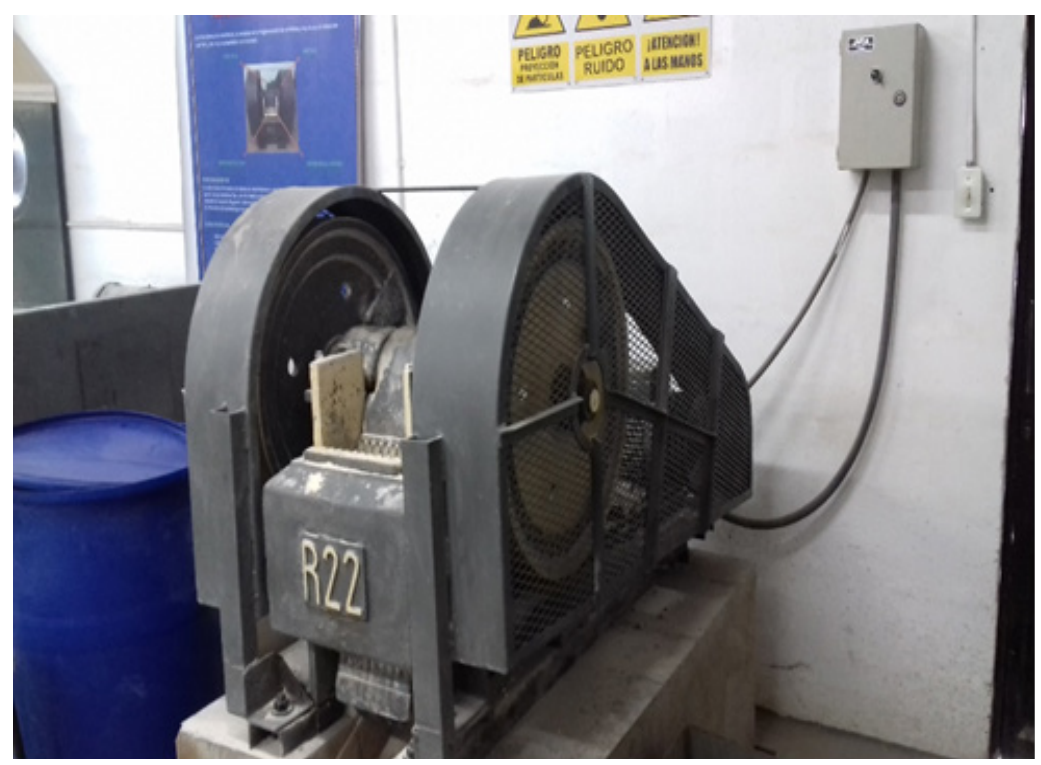

Fig. 2. MEM R 22 Jaw Crusher

Once this phase has been carried out, we proceed with the determination of the resistance to simple compression (UCS) of the daughter samples B. For this test, the appropriate equipment was used, which is intended for this purpose. The recommendations for the application are: a) Suitable for cylinders, cubes, beams and cores of mixtures. b) Test range from 2500 to $250000 \mathrm{lb}(11$ to $1112 \mathrm{KN})$ with an accuracy of $\pm 0.5 \%$ of the indicated load. c) Standard configuration includes test plates for 6 "x 12" $(150 \mathrm{~mm} \times 300 \mathrm{~mm})$ cylinders. The equipment used is presented in Figure 4. 


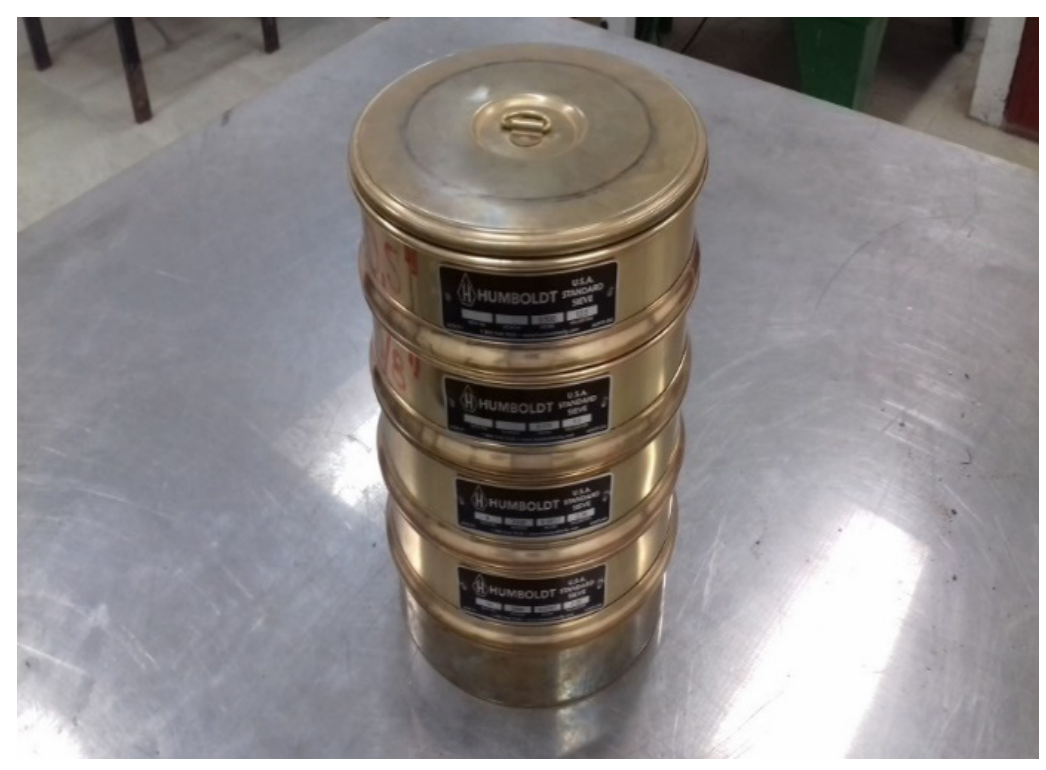

Fig. 3. Set of sieves for granulometric classification

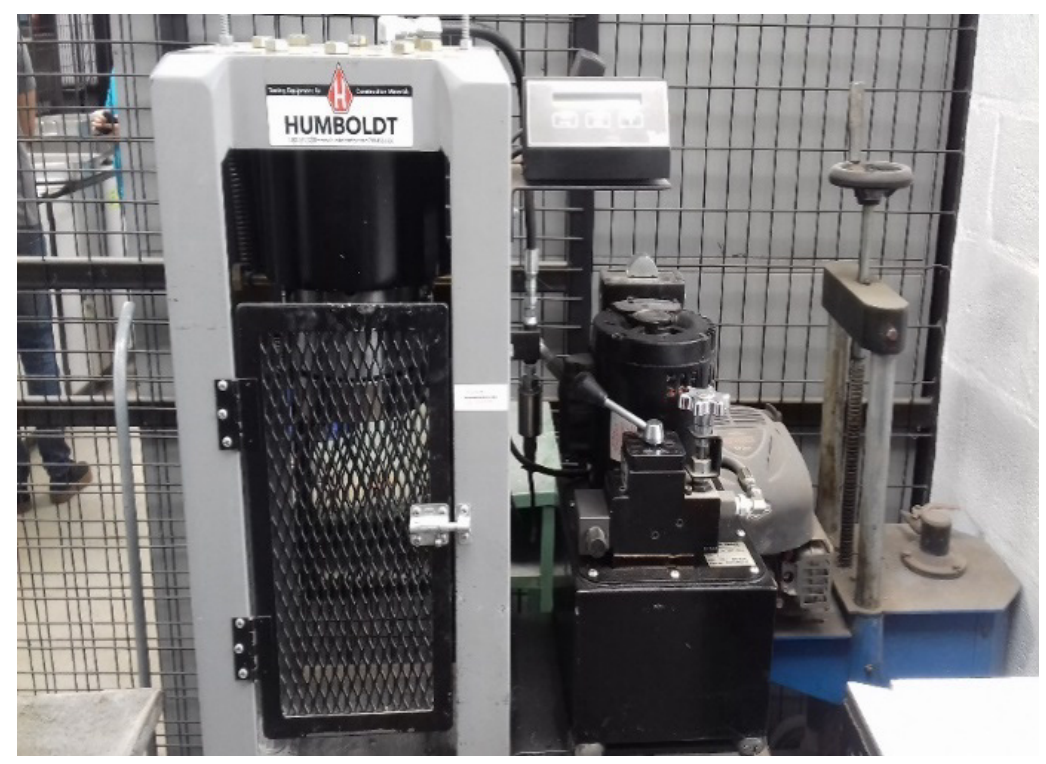

Fig. 4. Humboldt Compressive Strength Testing Equipment

\section{IV.RESULTS}

The results of the graphing of the different granulometric curves have presented three groups clearly located in ranges, in which, in the area of coarser granulometry, the groups of curves overlap, but not in the area of finer granulometry, where a separation of the curves can be clearly observed and said separation is also related or is a function of the values of resistance to simple compression. This can be seen in Figures 5, 6 and 7. 


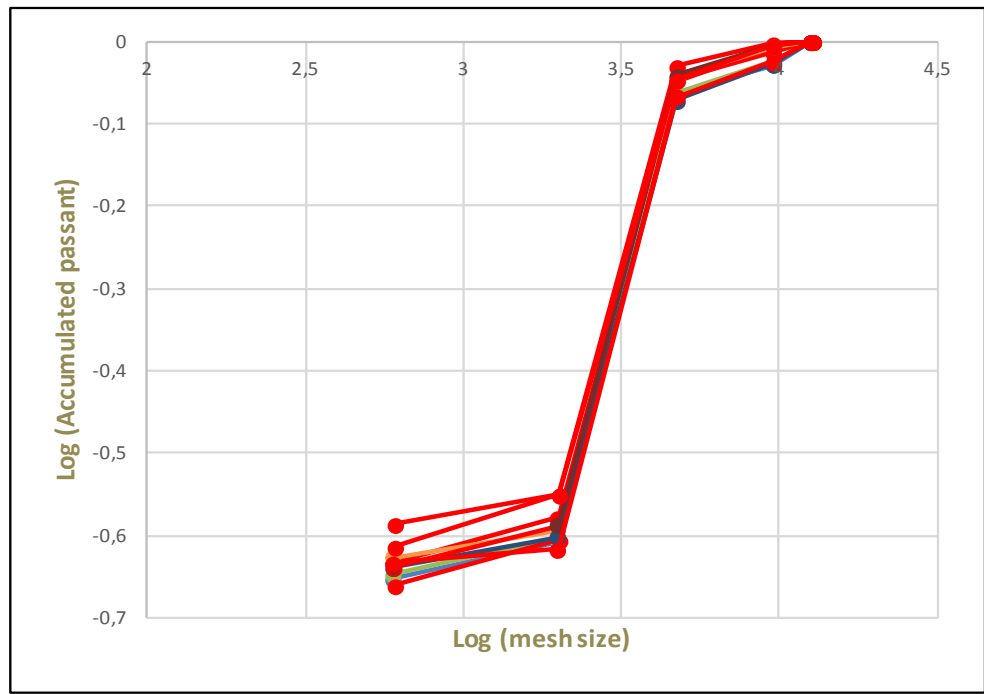

Fig. 5. Group 1 of curves with average UCS of $20 \mathrm{MPa}$

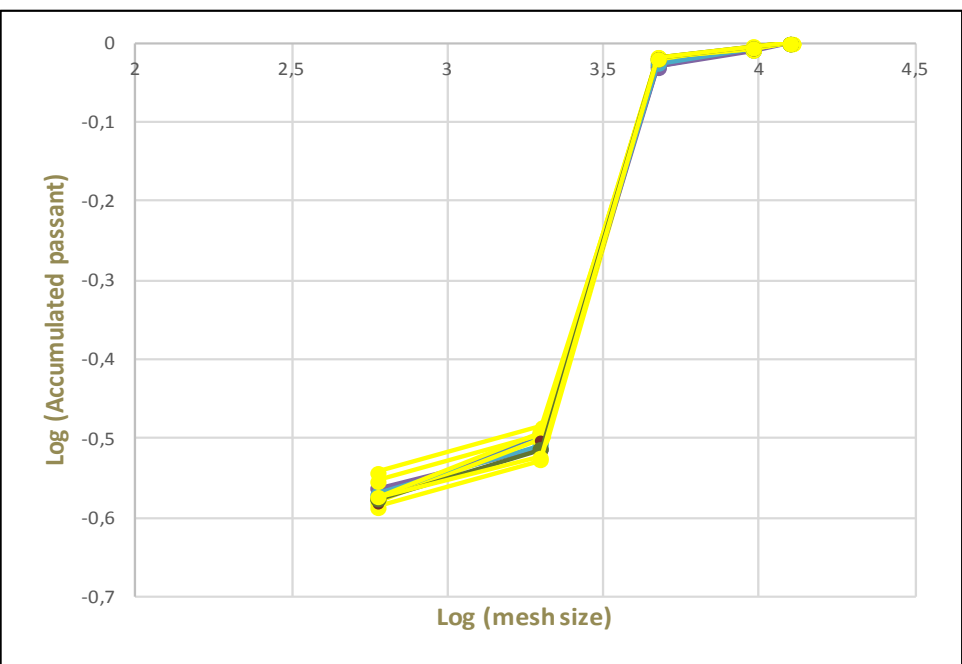

Fig. 6. Group 2 of curves with average UCS of $10 \mathrm{MPa}$

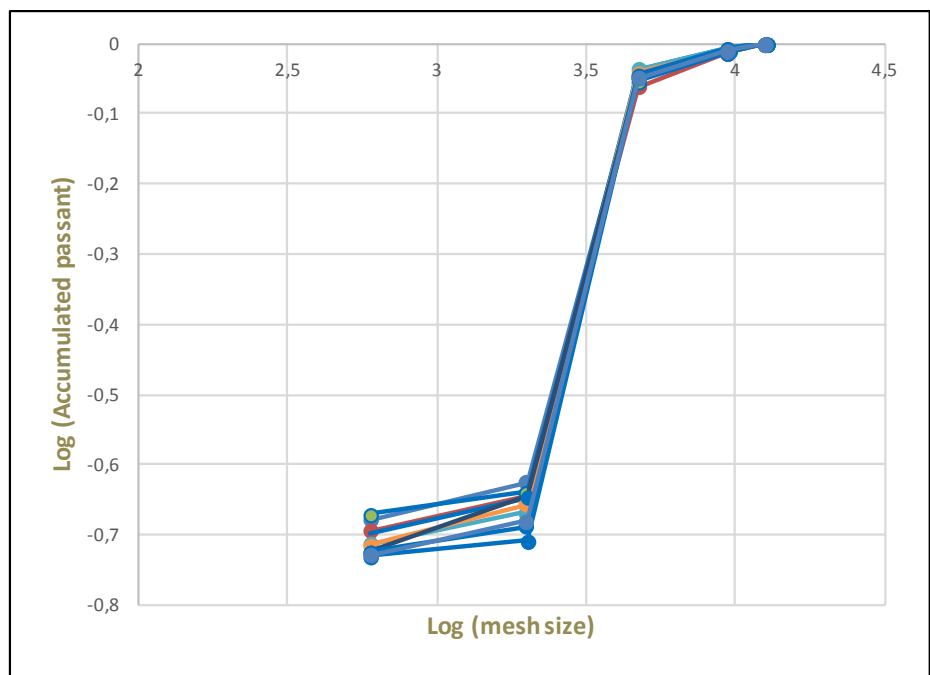

Fig. 7. Group 3 of curves with average UCS of $45 \mathrm{MPa}$ 
Given this arrangement of the granulometric curves, we can represent them in the same system, only graphing the non-common areas, that is, those with the finest granulometry; this is the three groups of curves, represented with different colors. Figure 8.

Once the results have been established, a graph is drawn up in which the different areas of fine granulometry are involved with their respective value of resistance to simple compression. It should be noted that this UCS value is the average of the values obtained from daughter B specimens, for each group. Figure 9.

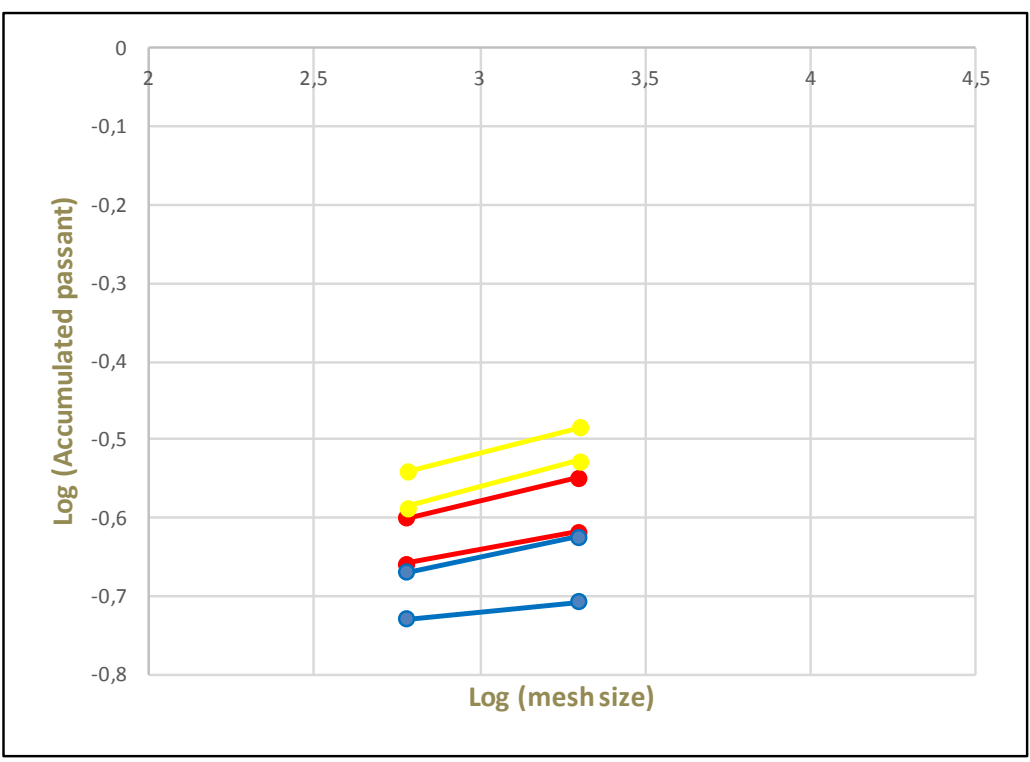

Fig. 8. Set of curves in finer granulometry area

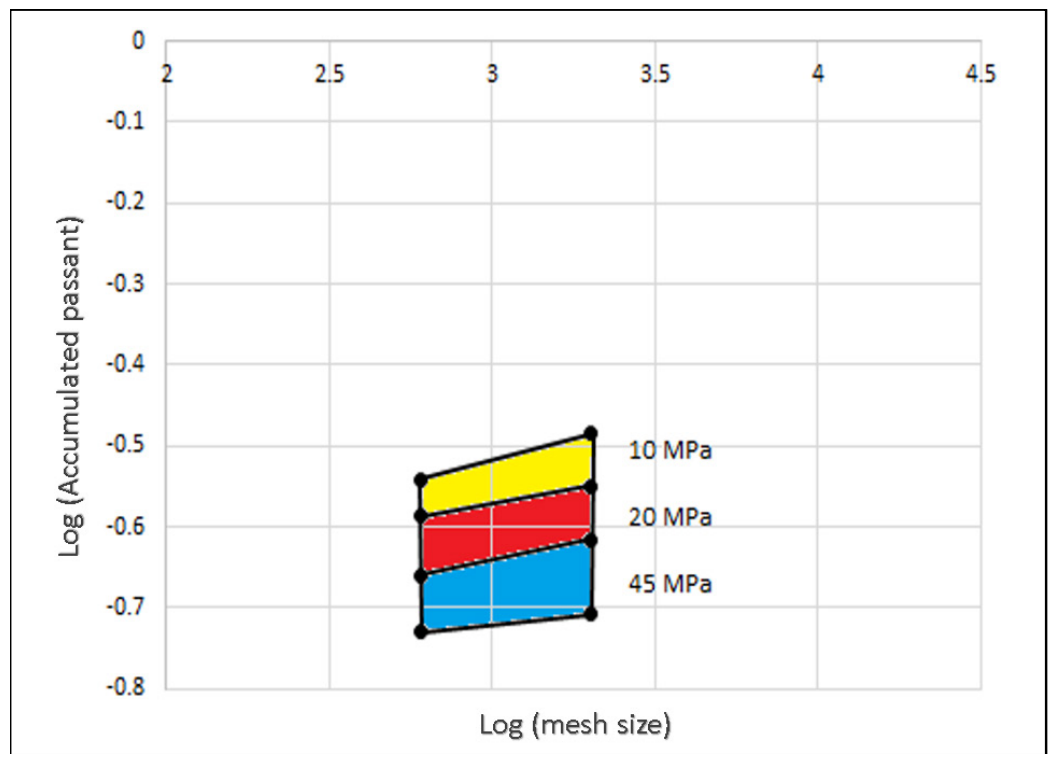

Fig. 9. UCS and fine granulometry characterization graph

The graph in figure 9 proposes to characterize the rocky material studied with an acceptable error, since, if we consider that the treated material has the same geological and mechanical properties, said material will be pigeonholed within the colored zones (yellow, red or blue), otherwise the material should be considered to send to the laboratory and proceed to a new study. It should be noted that the error is qualitative in nature.

\section{V.CONCLUSIONS}

After executing the crushing and granulometric classification tests of the specimens generated from the out- 
crops of the specific study area, it can be established that on the same rock there are differences in the granulometric curves, specifically with regard to fine granulometry, observing an enlargement of the separation spaces of said curves.

These differences of spaces in the granulometric curves allow us to establish zones in which the values of the fines are extended and, in this way, we can characterize these differences, since the UCS values for the mentioned curves also vary considerably. For the first group of curves that can be observed in figure 5 , all the curves generate an area in red color, which we can characterize with UCS of $20 \mathrm{MPa}$. We can observe the same in Figures 6 and 7 characterizing them with UCS values of $10 \mathrm{MPa}$ and $45 \mathrm{MPa}$, for the yellow and blue zones respectively.

It could be established that, when executing a new test of crushing and granulometric classification of a rock obtained from the area to be studied, if a granulometric curve with similar characteristics to those presented is generated, that is, this new curve is classified within one of these colored areas, it is not necessary to send samples to the laboratory, as it is a material with UCS values similar to those established in the graph of figure 9.

It can be seen in figure 9 that the colored spaces present a decrease in UCS values as we approach the horizontal axis, $\log$ (Mesh size), which may be the reason for deeper studies for the characterization of materials or minerals. in general terms. This study should focus on the area of fine materials, that is, under the $2 \mathrm{~mm}$ mesh, for example.

We believe that this work proposal will be very useful for mining projects in development since, by establishing the work mechanics for the characterization of the materials, training one worker is enough and, in this way, the sending of hundreds of samples to the laboratories, generating significant savings in time and money for the company.

Finally, it is suggested that this proposal be developed in other types of rock, with a greater number of elaborated specimens, different dimensions of specimens, that is to say, execute it with a modification of the different variables involved, in order to try to generalize it and make it effective. when using it in a mining project.

\section{ANNEXES}

TABLE 1. Results obtained from Group 1 with an average UCS of 20 MPa.

\begin{tabular}{|c|c|c|c|c|c|c|c|c|c|c|}
\cline { 2 - 10 } & \multicolumn{7}{|c|}{ Log (Accumulated Passant) } \\
\hline $\begin{array}{c}\text { Log (mesh } \\
\text { size) }\end{array}$ & 1 & 2 & 3 & 4 & 5 & 6 & 7 & 8 & 9 & 10 \\
\hline 3.978636948 & -0.02858 & -0.00712 & -0.02548 & -0.01198 & -0.00296 & -0.00722 & -0.02759 & -0.00611 & -0.02515 & -0.00609 \\
\hline 3.67669361 & -0.06364 & -0.04824 & -0.06333 & -0.04609 & -0.02862 & -0.04405 & -0.07225 & -0.04167 & -0.06778 & -0.04515 \\
\hline 3.301029996 & -0.60707 & -0.57826 & -0.60265 & -0.60622 & -0.5494 & -0.59333 & -0.60206 & -0.58848 & -0.61674 & -0.54932 \\
\hline 2.77815125 & -0.65183 & -0.63303 & -0.64736 & -0.65946 & -0.58643 & -0.62701 & -0.63846 & -0.6383 & -0.63314 & -0.61433 \\
\hline
\end{tabular}

TABLE 2. Results obtained from Group 2 with an average UCS of 10 MPa.

\begin{tabular}{|c|c|c|c|c|c|c|c|c|c|c|}
\cline { 2 - 10 } & \multicolumn{7}{|c|}{ Log (Accumulated Passant) } \\
\hline $\begin{array}{c}\text { Log (mesh } \\
\text { size) }\end{array}$ & 1 & 2 & 3 & 4 & 5 & 6 & 7 & 8 & 9 & 10 \\
\hline 3.978636948 & -0.00773 & -0.00579 & -0.00427 & -0.00974 & -0.00858 & -0.00694 & -0.00583 & -0.00853 & -0.00587 & -0.00588 \\
\hline 3.67669361 & -0.02851 & -0.02587 & -0.02289 & -0.02989 & -0.02683 & -0.0195 & -0.01828 & -0.01777 & -0.01952 & -0.0201 \\
\hline 3.301029996 & -0.49485 & -0.48451 & -0.52715 & -0.51162 & -0.50792 & -0.49386 & -0.49157 & -0.50043 & -0.51361 & -0.52359 \\
\hline 2.77815125 & -0.57724 & -0.54068 & -0.58642 & -0.5632 & -0.57033 & -0.55398 & -0.57601 & -0.58095 & -0.57682 & -0.5743 \\
\hline
\end{tabular}


TABLE 3. Results obtained from Group 3 with an average UCS of 45 MPa.

\begin{tabular}{|c|c|c|c|c|c|c|c|c|c|c|}
\cline { 2 - 10 } & \multicolumn{7}{|c|}{ Log (Accumulated Passant) } \\
\hline $\begin{array}{c}\text { Log (mesh } \\
\text { size) }\end{array}$ & 1 & 2 & 3 & 4 & 5 & 6 & 7 & 8 & 9 & 10 \\
\hline 3.978636948 & -0.01355 & -0.01353 & -0.01242 & -0.00549 & -0.00614 & -0.0079 & -0.01016 & -0.01032 & -0.00709 & -0.01035 \\
\hline 3.67669361 & -0.04535 & -0.06215 & -0.05393 & -0.03735 & -0.03624 & -0.04103 & -0.04543 & -0.04816 & -0.04439 & -0.0483 \\
\hline 3.301029996 & -0.62446 & -0.64461 & -0.63916 & -0.64809 & -0.66779 & -0.65654 & -0.64357 & -0.70745 & -0.68797 & -0.67956 \\
\hline 2.77815125 & -0.67882 & -0.69322 & -0.67076 & -0.69655 & -0.7126 & -0.71492 & -0.72327 & -0.7294 & -0.72369 & -0.7282 \\
\hline
\end{tabular}

\section{REFERENCES}

[1] F. Blyth, M. de Freitas. Geología para Ingenieros. México: CEGSA, 2003.

[2] F. Escolano, A. Mazariegos de la Serna. Guía de reconocimiento de rocas en Ingeniería Civil. España: Editorial Garceta, Escuela Técnica Superior de Ingeniería Civil, Universidad Politécnica de Madrid, 2014.

[3] G. Stefano, J. Segovia. Notas del curso de Arte Minero I. Ecuador: Universidad del Azuay, 1991.

[4] A. Maistri. Guía al Curso de Tratamiento de Minerales y a las Prácticas de Laboratorio. Ecuador: Universidad del Azuay, 1993.

[5] O. Bustamante. Conminución de Minerales Trituración y Molienda. Colombia: Instituto de Minerales CIMEX, Universidad Nacional de Colombia-Sede Medellín, 2006.

[6] E. Feijoo, C. Flores and B. Feijoo, "The Concept of the Granulometric Area and Its Relation with the Resistance to the Simple Compression of Rocks," 2019 7th International Engineering, Sciences and Technology Conference (IESTEC), Panama, Panama, 2019, pp. 52-56.

[7] E. Feijoo, C. Iñiguez, "Corte en rocas y su relación con la resistencia a compresión simple”, RISTI, N.o E 30, pp. 59-67, junio 2020.

[8] M. Galván. Mecánica de Rocas. Correlación entre la Resistencia a Carga Puntual y la Resistencia a Compresión Simple. Colombia: Universidad del Valle, 2015.

[9] W. Marín. Evaluación de parámetros materiales de fractura en roca intacta. Colombia: Universidad Nacional de Colombia sede Medellín, 2017.

[10]E. Feijoo, J. Padrón, "La resistividad de rocas y su relación con la resistencia a compresión simple en mina", UCT, vol. 24, Núm. 99, pp. 61-67, abril 2020.

\section{RESUMEN CURRCIULAR}

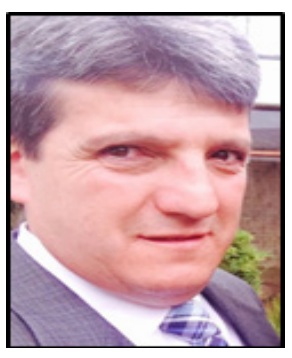

Patricio Feijoo, Mining Engineer, graduated from the University of Azuay (Cuenca-Ecuador), with studies and internships in: Bolivia, Brazil, Spain, Australia in areas of geology, geophysics and development of mining activities. He is linked to teaching at the University of Azuay.

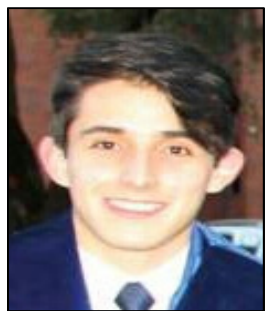

Bernardo Feijoo, Civil Engineer, graduated from the University of Azuay (Cuenca-Ecuador), with studies and internships in: Colombia, Peru, Cuba and Panama, in areas of the characterization of materials and processes for making cements and concretes. 